УДК: 355.3

Олег Миколайович Остапець

Генеральний штаб Збройних Сил Украӥни, Київ, Украӥна

\title{
ВИКОРИСТАННЯ МЕТОДІВ ТЕОРІЇ КВАЛІМЕТРИЧНИХ ВИМІРЮВАНЬ ДЛЯ ОЦІНЮВАННЯ ГОТОВНОСТІ ЗБРОЙНИХ СИЛ ДЕРЖАВИ ДО ВІДСІЧІ ЗБРОЙНОЇ АГРЕСІЇ
}

Набуття ЗС Украӥни необхідних спроможностей для гарантованого виконання свого конституційного обов'язку потребує наукових досліджень напрямів $i$ конкретних заходів щзодо оцінювання стану їх розвитку та готовності до застосування. Зазначене визначає актуальність та необхідність вивчення ивього питання.

3 огляду на це в статті розглянуто зміст диференційного методу теорії кваліметричних вимірювань та наведено обгрунтування можливості його використання для оцінювання готовності збройних сил держави до відсічі збройної агресії та подальшого їх розвитку.

Метою даної статті є наведення переваг у використанні методів теорії кваліметричних вимірювань для представлення якісних показників готовності ЗС держави кількісними значеннями.

Результати наведеного в статті дослідження можуть бути використаними вищим воєннополітичним керівництвом країни під час прийняття рішень щзодо подальшого розвитку ЗС України, їх підготовки до застосування, а також в навчальному процесі Національного університету оборони Украӥни імені Івана Черняховського

Ключові слова: збройні сили, показники оцінювання, теорія кваліметричних вимірювань, абсолютний показник якості, диференційний метод, оборонні витрати, чисельність Збройних Сил, озброєння та військова техніка.

\section{Вступ}

Оцінювання впливу значень показників, які безпосередньо або опосередковано відображають готовність 3С держави до відсічі збройної агресії, потребує розроблення нових або використання (пристосування для цієї мети) вже відомих сучасній науці методів вимірювання.

Постановка проблеми. Під готовністю 3С держави до відсічі збройної агресії пропонується розуміти ї спроможність виконати визначені завдання за умов відповідності встановленим стандартам їх ресурсного забезпечення та підготовки.

За академічним тлумачним словником української мови "готовність - це стан, в якому об’єкт придатний для використання або споживання, приготовлений, який вже склався, набув досвіду, досяг майстерності, тощо.” [1].

Wikipedia [2] трактує бойову готовність як “визначений стан збройних сил, який характеризує їх здатність організовано, у визначені строки розпочати воєнні дії i успішно виконувати поставлені бойові завдання".

Тобто, ці визначення дають підстави стверджувати, що готовність - це сукупність власних характеристик продукції (об'єкта), які стосуються її здатності задовольняти встановлені i передбачені потреби, що в кваліметрії називається якістю продукції. [3, 4].

Отже, маємо формальні підстави застосувати кваліметричні вимірювання для отримання числових оцінок готовності Збройних Сил України до відсічі збройної агресії.
Аналіз останніх досліджень і публікацій будівництва та розвитку ЗС України, проведених протягом 2010-2018 років свідчить, що більшість 3 них були спрямовані на будівництво та розвиток, перш за все, структурних складових 3С, а не на розвиток ЗС України в цілому як стратегічного угруповання військ (сил) на території держави, якими вони фактично $\epsilon$.

Дослідження розвитку структурних складових 3С України проведених вітчизняними вченими Руснаком I.C., Телелимом В.M., Загоркою О.M., Затинайко О.П., Пундою Ю.В., Фроловим В.С., Дєнєжкіним М.M. дозволяють, але 3 певними застереженнями, застосовувати їх для обгрунтування напрямів розвитку ЗС України в цілому.

Дослідження, проведені В.П.Мотало, стосуються методології та проблематики кількісного оцінювання якості продукції для розширення можливостей кваліметрії щодо достовірності та точності отриманих оцінок якості продукції.

Метою статті $\epsilon$ обгрунтування можливості застосування методів теорії кваліметричних вимірювань для оцінювання готовності 3С до відсічі збройної агресії.

\section{Виклад основного матеріалу дослідження}

Метою будь-якого вимірювання є отримання кількісної достовірної інформації або якісної оцінки стосовно об'єкта вимірювання. Якщо в 
якості об'єкта вимірювання виступають ЗС держави, то необхідність отримання такої достовірної інформації існує постійно. В статті розглянуто результати дослідження можливості використання методів теорії кваліметрії (кваліметрія походить від латинської (quales -

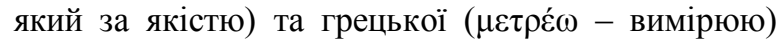
для вимірювання кількісних значень показників готовності ЗС до відсічі збройної агресії.

За своєю сутністю кваліметричні вимірювання - це вимірювання, які дають змогу отримати числову оцінку якості досліджуваної продукції, а саме - рівень іiі якості. Кваліметрія здійснює оцінювання шляхом порівняння фізичних, економічних, естетичних та інших показників 3 еталонами. У метрології також $\epsilon$ еталони, стандарти, але вони, як правило, стабільні й історично незмінні (метр, кілограм та ін), а кваліметричні еталони можуть змінюватись, вони $\epsilon$ функцією часу, природного i соціального середовища.

У зв'язку 3 широкою сферою застосування кваліметрії сьогодні ії̈ вважають дисципліною, що вивчає проблему оцінювання якості будь-яких об'єктів, предметів і процесів. При цьому забезпечення якості і технологій якості різної продукції $\epsilon$ основним напрямком використання методів кваліметрії. Таким чином, кваліметрія як наука об'єднує кількісні методи оцінки якості, що використовуються для обгрунтування управлінських рішень та суміжних 3 ними питань управлінської діяльності [4].

Стосовно 3С держави кваліметрія має здійснювати кваліметричні оцінки вимірюванням $\mathrm{i}$ порівнянням числових значень показників, які безпосередньо або опосередковано відображають готовність ЗС держави до відсічі збройної агресії. Крім того, за умови відповідності значень зазначених показників нормативним або еталонним виникає реальна можливість: отримати синергетичний ефект готовності ЗС до відсічі збройної агресії та обгрунтувати управлінські рішення щодо напрямів їх розвитку.

Метою статті $\epsilon$ обгрунтування можливості застосування методів теорії кваліметричних вимірювань для оцінювання готовності ЗС до відсічі збройної агресії.

Викладення основного матеріалу. На відміну від класичної метрології, теорія якої є достатньо розробленою [6-8], теорія кваліметрії через специфічність об'єкту дослідження розвинута недостатньо. Тому подальший розвиток теоретичних основ кваліметрії для кількісного вимірювання стану готовності та подальшого обгрунтування конкретних напрямів розвитку ЗС України $\epsilon$ новим i актуальним науковопрактичним завданням.

Перевага у використанні методів теорії кваліметричних вимірювань обгрунтовується, в першу чергу, можливістю представлення якісних показників готовності 3С держави кількісними значеннями. Теоретично кваліметричні вимірювання складаються із двох основних етапів [9]: вимірювання різних показників (властивостей) продукції - механічних, просторових, електричних, магнітних, теплових, хімічного складу тощо;

оцінювання рівня якості продукції на основі проведених вимірювань значень різних показників (властивостей).

Загалом перший етап кваліметричних вимірювань $є$ суто технологічною частиною; другий етап $\epsilon$ опрацюванням отриманих результатів 3 метою визначення рівня якості досліджуваної продукції. Такий підхід до кваліметричних вимірювань 3 позиції теорії вимірювань дозволяе вважати їх одним із видів непрямих вимірювань, а кваліметрію - одним із розділів метрології [10].

Відповідно до мети проведеного дослідження зміст кожного із етапів кваліметричного вимірювання для ЗС держави було інтерпретовано наступним чином:

перший, вимірювання кількісних значень різних показників, які на стратегічному рівні безпосередньо i критично визначають та впливають на готовність ЗС до відсічі збройної агресії, а саме: бюджетне фінансування; чисельність; організаційна структура (види, роди військ); професійна підготовка особового складу (загальноосвітній рівень, класність фахівців, співвідношення чисельності офіцерів і солдат); кількість (відсоток) готових частин в ЗС держави; кількість основних видів озброєння та військової техніки; відсоток справного ОВТ; кількість запасів матеріальних засобів тощо;

другий, оцінювання готовності ЗС до відсічі збройної агресії за результатами вимірювань значень кожного 3 перерахованих вище або вибраних одиничних показників, які їі визначають (характеризують).

Відомі два основних методи оцінювання достовірної інформації стосовно об'єкта вимірювання - диференційний і комплексний.

Диференційним називають метод, який грунтується на використанні одиничних показників стану готовності 3С до застосування. При цьому одиничним вважають показник, що характеризує одну із властивостей готовності $3 \mathrm{C}$, наприклад укомплектованість особовим складом тощо. Одиничні показники готовності ЗС до застосування у свою чергу поділяються на абсолютні та відносні.

Абсолютний показник готовності ЗС Pi (i=1, 2, .., n, де n-число показників) чисельно дорівнює значенню і-ої властивості рі показника i виражається у їі одиницях вимірювання. Отже, у процедурі оцінювання готовності 3С до застосування він $є$ безпосередньо вимірюваною величиною, а для оцінюваної стану готовності ЗС такого як “достатня-недостатня" отримане значення показника $\mathrm{Pi}$ порівнюють із базовим (еталонним) значенням цього показника $\mathrm{Pb}, \mathrm{i}$, тобто iз значенням показника готовності 3С, прийнятим за основу під час порівняльного оцінювання. В цілому співвідношення між показниками $\mathrm{Pi}$ та $\mathrm{Pb}, \mathrm{i}$ 
залежно від виду оцінюваної готовності ЗС виражається формулами $\mathrm{Pi} \leq \mathrm{Pb}, \mathrm{i}$ або $\mathrm{Pi} \geq \mathrm{Pb}, \mathrm{i}$.

Однак вказані співвідношення не дають чіткої відповіді щодо рівня готовності ЗС, тобто наскільки він “задовольняє” або "незадовольняє" цю вимогу, тому у кваліметрії користуються відносним показником готовності $3 \mathrm{C} \mathrm{Ki}$, який визначають як

$$
\begin{aligned}
& \mathrm{Ki}= \frac{P i}{P b, i} \quad \text { у випадку } \mathrm{Pi} \leq \mathrm{Pb}, \mathrm{i} \\
& \mathrm{Ki}=\frac{P b, i}{P i} \quad \text { у випадку } \mathrm{Pi} \geq \mathrm{Pb}, \mathrm{i}
\end{aligned}
$$

Значення одиничних відносних показників готовності $3 \mathrm{C} \mathrm{Ki} \mathrm{завжди} \mathrm{лежать} \mathrm{у} \mathrm{межах} 0 \leq \mathrm{Ki} \leq 1$, але залежно від фактичного значення абсолютного показника готовності 3С $\mathrm{Pi}$, числове значення відносного показника Кі змінюється по-різному, що дозволяє виділити дві групи таких показників.

Перша група, коли до підвищення рівня готовності 3С призводить збільшення значення одиничного оцінюваного абсолютного показника готовності $\mathrm{Pi}$ i, відповідно, до збільшення одиничного відносного показника готовності $\mathrm{Ki}$, тобто має виконуватись умова $\mathrm{Ki} \rightarrow 1$.

У другій групі навпаки: коли до підвищення рівня готовності ЗС призводить зменшення значення одиничного оцінюваного абсолютного показника готовності Pi i, відповідно, зменшення одиничного відносного показника готовності Ki, тобто має виконуватися умова $\mathrm{Ki} \rightarrow 0$.

Наприклад, у випадку оцінювання готовності ЗС до застосування до першої групи одиничних абсолютних показників можна віднести кількість готових до застосування за призначенням військових частин, а до другої - кількість неготових або обмежено готових військових частин.

Отже, під час реалізації диференційного методу оцінювання готовності ЗС до застосування

\section{Лimepamypa}

1. Академічний тлумачний словник української мови URL:: www.sum.in.ua/s/ghotovnistj. 2. Wikipedia URL:: https//uk.m.wikipedia. org/wiki/Бойова_готовність. 3. Якість продукції. Оцінювання якості. Терміни та визначення: ДСТУ 2925-94. - [ Чинний від 1996-01-01 ]. - Київ: Держстандарт України, 1995, - 27 с. (Державний стандарт України). 4. Системи управління якістю. Основні положення та словник термінів: ДСТУ ISO 9000: 2007. - [ Чинний від 2008-01-01 ]. - Київ: Держстандарт України, 2008, - 35 с. - (Державний стандарт України). 5. Мотало В.П., Мотало А.В., Стадник Б.І. Метрологія, кваліметрія та кваліметричні вимірювання:теорія і практика / Мотало В.П., Мотало A.B., Стадик Б.I. // URL::: www.irbisnbuv.gov.ua/.../cgiirbis_64.exe?.. 6. Шишкин И.Ф. Теоретическая метрология: Учебник для вузов /Шишкин здійснюється роздільне порівняння абсолютних показників 3 їх базовими (еталонними) значеннями, що є перевагою цього методу. Однак вважається недоліком цього методу неврахування рівня впливу окремих абсолютних показників на загальний стан готовності 3С, тобто їх вагомості, особливо коли цих показників багато.

Більш досконалим методом оцінювання готовності ЗС вважається комплексний метод, який грунтується на використанні комплексних показників готовності, що одночасно характеризують декілька властивостей абсолютних показників готовності. Однак усереднення одиничних показників різної природи без індивідуального порівняння однорідних показників є його недоліком [10].

3 огляду на це, метод комплексного оцінювання готовності ЗС до застосування в цьому дослідженні не розглядався.

\section{Висновки і перспективи подальших досліджень}

Методи теорії кваліметричних вимірювань надають можливість 3 достатнім ступенем об'єктивності оцінювати готовність ЗС до застосування за результатами вимірювань широкого спектру показників, на підставі значень яких існує можливість рекомендувати конкретні напрями подальшого розвитку ЗС України.

Використання методу теорії кваліметричних вимірювань спільно 3 даними інформаційноаналітичної системи підтримки оборонного планування "Ресурс" дозволяє оцінювати за окремими абсолютними показниками готовність 3С України до відсічі збройної агресії та використовувати отримані результати при плануванні заходів утримання та розвитку Збройних Сил України.

Безпосереднє застосування диференційного методу теорії кваліметричних вимірювань дозволяє здійснювати роздільне порівняння окремих показників (абсолютних) 3 їх базовими (еталонними) значеннями, що є його перевагою.

И.Ф./ - М.: Издательство стандартов, 1991. - 471 с. 7. Пфанцагль И. Теория измерений / Пфанцагль И.; Пер. с англ. В.Б. Кузьмина/. - М.: Мир, 1976. - 166 с.. 8. Мотало В.П. Система оцінювання якості продукції 3 використанням віртуальної міри якості /Стадик Б.І, Мотало В.П., Мотало А.В. // Стандартизація, сертифікація, якість. - 2009. - № 2. - С. 48-55.. 9. Якість продукції. Оцінювання якості. Терміни та визначення: ДСТУ 2925-94. - [Чинний від 1996-01-01]. - К.: Держстандарт України, 1995. - 27 с. - (Державний стандарт України). 10. Мотало В.П., Мотало А.В. Аналіз основних проблем теорії кваліметричних вимірювань / Мотало В.П, Мотало А.В. // Стандартизація, сертифікація, якість, 2011. - № 1. - С. 60-64. .

\section{ИСПОЛЬЗОВАНИЕ МЕТОДОВ ТЕОРИИ КВАЛИМЕТРИЧЕСКИХ ИЗМЕРЕНИЙ ДЛЯ ОЦЕНКИ ГОТОВНОСТИ ВООРУЖЕННЫХ СИЛ ГОСУДАРСТВА К ОТРАЖЕНИЮ АГРЕССИИ}




\title{
Олег Николаевич Остапец
}

\section{Генеральный штаб Вооруженных Сил Украины, Киев, Украина}

Приобретение ВС Украины необходимых возможностей для гарантированного выполнения своих конституционных обязанностей требует научных исследований направлений и конкретных мероприятий по оценке состояния их развития и готовности к применению. Это определяет актуальность и необходимость изучения этого вопроса.

Учитывая это в статье рассмотрень содержание дифференциильного метода теории квалиметрических измерений и приведено обоснование возможности его использования для оценки готовности вооруженных сил государства к отражению вооруженной агрессии и дальнейшего их развития.

Целью данной статьи является наведение преимуществ в использовании методов теории квалиметрических измерений для представления качественных показателей готовности ВС государства количественными значениями.

Результаты приведенного в статье исследования могут быть использованы высшим военнополитическим руководством странь при принятии решений относительно дальнейшего развития ВС Украины, их подготовки к применению, а также в учебном процессе Наџионального университета обороны Украины имени Ивана Черняховского

Ключевые слова: вооруженные силы, показатели оценки, теория квалиметрических измерений, абсолютный показатель качества, дифференииальный метод, оборонные расходы, численность вооруженных сил, вооружение и военная техника.

\section{USE OF METHODS OF QUALIMETRIC MEASUREMENT THEORY FOR PREPARATION EVALUATION ARMED FORCES OF THE STATE TO THE ARRANGEMENT OF ARMED FORCES}

\author{
Oleg Ostapets
}

\section{General Staff of the Armed Forces of Ukraine, Kyiv, Ukraine}

Acquisition of the Armed Forces of Ukraine necessary capacities for the guaranteed fulfillment of its constitutional duty requires scientific research of directions and concrete measures for assessing their state of development and readiness for use. The above determines the relevance and necessity of studying this issue.

In view of this, in the article the content of the differential method of the theory of qualimetric measurements is considered and the justification of the possibility of its use for assessing the readiness of the armed forces of the state to withstand armed aggression and their further development is presented.

The purpose of this article is to give preference to the use of methods of the theory of qualimetric measurements in order to represent the qualitative indicators of the readiness of the Armed Forces of the country by quantitative values.

The results of the research presented in this article can be used by the highest military-political leadership of the country when making decisions on the further development of the Armed Forces of Ukraine, their preparation for use, as well as in the educational process of the National University of Defense of Ukraine named after Ivan Chernyakhovsky

Key words: armed forces, evaluation indicators, theory of qualimetric measurements, absolute quality index, differential method, defense expenditures, number of Armed Forces, armament and military equipment.

\section{References}

1. Academic Explanatory Dictionary of the Ukrainian language URL: www.sum.in.ua/s/ghotovnistj .. 2. Wikipedia URL: https // uk.m.wikipedia. org / wiki / Fighting_foot. 3. Product quality. Quality assessment. Terms and definitions: DSTU 2925-94. - [Effective from 01/01/1996]. - Kyiv: Gosstandart of Ukraine, 1995, - 27 p. - (State standard of Ukraine). 4. Quality management systems. Key Terms and Glossary of Terms: DSTU ISO 9000: 2007. - [Effective from 01/01/2008]. - Kyiv: Gosstandart of Ukraine, 2008, 35 p. - (State standard of Ukraine). 5. Motalo V.P., Motalo AV, Stadnik B.I. Metrology, Qualimetry and Qualimetric Measurements: Theory and Practice / Motalo VP, Motalo AV, Stadik B.I. // URL ::: www.irbisnbuv.gov.ua/.../cgiirbis_64.exe ?. . 6. Shishkin I.F. Theoretical Metrology: A Textbook for High Schools
/ Shishkin IF / - Moscow: Publishing Standards, 1991. - 471 p. 7. Pfantsagl I. Theory of Measurements / Pfantsagl I .; Per. from english VB Kuzmin /. - M .: Mir, 1976. - 166 s .. 8. Motalo V.P. The system of quality assessment of products using a virtual degree of quality / Stadique B.I., Motalo V.P., Motalo A.V. // Standardization, certification, quality. - 2009. - No. 2. - P. 48-55 .. 9. Product quality. Quality assessment. Terms and definitions: DSTU 2925-94. - [Effective from 01/01/1996]. - K .: Gosstandart of Ukraine, 1995. - 27 p. - (State standard of Ukraine). 10. Motalo V.P., Motalo A.V. Analysis of the main problems of the theory of qualimetric measurements / Motalo VP, Motalo AV // Standardization, certification, quality, 2011. - № 1. - P. 6064. 